\title{
Freud e a Educação como formação integral do sujeito
}

Maria Judith Sucupira da Costa Lins ${ }^{1}$

Resumo: Este artigo analisa a possibilidade da contribuição dos conceitos de Freud para a Educação. Psicanálise e Educação são áreas de estudo com algumas ideias semelhantes. O foco básico é que pensar o inconsciente como poder radical não é possível para a Educação. Professores devem organizar seu conhecimento com a finalidade de relacionar Freud e a Educação para o bem dos alunos. Professores não devem negar a existência do inconsciente, mas devem entender que Liberdade e Racionalidade são os principais traços dos seres humanos. Necessitamos afirmar o papel de ambos e estudar sobre o inconsciente. Este desafio impulsiona a atividade educacional.

Palavras-chave: Inconsciente. Liberdade. Racionalidade.

Abstract: This paper analyzes the possibility of the contribution of Freud's concepts to Education. Psychoanalysis and Education are study domains of with some similar ideas. The basic focus is that seeing the unconscious as a radical power is not possible for Education. Teachers must organize their knowledge in order to relate Freud and Education, for the students' own good. Teachers should not deny the existence of the unconscious, but understand that Freedom and Rationality are the main traces of human beings. We need to affirm the role of both and study the unconscious. This challenge boosts educational activity.

Keywords: Unconscious. Freedom. Rationality.

\section{Introdução}

Observamos em nossa realidade que estudos sobre a teoria psicanalítica de Freud concernentes à Educação, notadamente como formação integral do sujeito, não são muito frequentes, embora venham crescendo. Psicanálise e Educação se apresentam como áreas de aproximação e distanciamento, de modo que não há especificamente um olhar sobre essas com o objetivo que pretendemos para esse artigo. Na realidade, ao buscarmos esses trabalhos, sejam ensaios ou pesquisas, encontramos tentativas de ligação entre os conceitos freudianos e a prática pedagógica, de forma esporádica, mas sem que haja propriamente uma sistematização.

Também não pretendemos chegar a um trabalho conclusivo com o presente artigo, pois não é o espaço adequado para esse objetivo. O tema que foi escolhido para discussão é muito complexo e merece pesquisas e estudos mais extensos. Nesse espaço de um artigo, procuraremos apresentar o problema da formação integral do sujeito e como essa proposta da Educação pode ser vista em confronto com o que Freud apresenta em sua obra. Alguns tópicos que nos parecem fundamentais para

${ }^{1}$ Professora Associada da Faculdade de Educação UFRJ. Coordenadora de Pesquisas do Grupo de Pesquisa sobre Ética e Educação - GPEE/UFRJ. Membro da Academia Brasileira de Educação.

APRENDER - Cad. de Filosofia e Psic. da Educação

Vitória da Conquista

Ano XI

ก. 17

p. 24-34

jan./jun.2017

DOI: $10.22481 /$ aprender.v0i17.2996

ISSN online: $2359-246 \mathrm{X}$ 
a compreensão de uma possível relação entre o pensamento freudiano e a conceituação que temos de Educação como formação integral do sujeito.

Em outra perspectiva, já fizemos anteriormente uma abordagem em que buscávamos a aproximação entre as ideias freudianas, as instâncias básicas de seu modelo de personalidade e os propósitos da educação (SUCUPIRA LINS, 2002) com enfoques particulares que não serão aqui repetidos. No referido artigo, foram destacadas os conceitos e ideias principais que foram analisados à luz de autores que traziam uma contribuição sobre o sentido da educação em uma profundidade filosófica interessante ao situar o homem em uma posição especial de razão e discernimento no mundo. O objetivo foi diferente, pois se limitou a discutir a possibilidade de uma antropologia freudiana que pudesse fornecer subsídios para a prática educativa e a autora centralizou sua argumentação no papel do inconsciente definido por Freud (1951c) em relação ao conceito de ser humano como antrhopos.

Em contrapartida ao inconsciente e seu papel, foram analisadas as questões primordiais da liberdade e vontade, peculiares ao ser humano. A ideia chave foi apontar como cada pessoa poderia tomar a direção de sua própria vida. Chegamos à conclusão que pensar a educação a partir daquele embasamento apresentado mostrava a impossibilidade de conciliação entre o predomínio do inconsciente segundo o pensamento freudiano e a premissa de liberdade que é uma característica essencial do ser humano.

Certamente não poderemos nos distanciar muito do que foi a argumentação discutida naquele escrito sobre a antropologia freudiana e a educação, pois o problema da formação integral do sujeito será estudado nesse artigo a partir da mesma premissa. Ampliando no presente artigo aquela ideia originalmente apresentada, busca-se encontrar reforço no conceito central da razão (MACINTYRE, 2006) como instância nuclear e ao mesmo tempo se tornar autoconsciente das exigências morais e sociais.

Não repetiremos nesse artigo os conteúdos freudianos, por não nos parecerem necessários devido ao fato de serem demais conhecidos dos estudiosos da área de psicologia e de educação, pois nosso intento é trazer autores que nos permitam chegar a uma conclusão sobre em que medida a relação entre Freud e a Educação como formação integral do sujeito seria possível. As instâncias e os modelos de personalidade freudiano são o ponto de partida que tomamos para essa análise filosófica original e por isso temos que nos deter mais profundamente nos argumentos e pensamentos desse campo do saber.

Consideramos que a teoria de Freud é, sem dúvida alguma, uma contribuição fundamental para o estudo da Psicologia do Desenvolvimento desde a análise dos primeiros anos de vida da criança. Isto, no entanto, não significa necessariamente que o mesmo possa ser dito inteiramente para a Educação enquanto projeto de formação integral do ser humano.

Concordamos com Lickona (1971) ao afirmar que "a visão de Freud do funcionamento humano, se válida, levanta importante questões sobre educação", mas fazemos, desde logo, a mesma 
ressalva que o renomado professor norte-americano ao se interrogar sobre como é possível à educação afetar o instinto na medida em que este é peça crucial na explicação freudiana. Lickona (1971) indaga ainda se o instinto seria naturalmente uma garantia do que a criança viria a se constituir, tornando assim superficial toda a atividade pedagógica. Pergunta também sobre como seria possível a construção do caráter se a educação desistisse de seu intuito de formação da pessoa e consolidação da personalidade autoconsciente.

\section{Filosofia da Educação e suas contribuições para a discussão}

Cabe inicialmente, e é o que faremos nesse momento em que pretendemos discutir o problema já enunciado, procurar entender o que afirmamos com o termo Educação, que segundo Sucupira (1980, p. 28) é assim identificado:

As atividades intencionalmente exercidas sobre o desenvolvimento de uma personalidade com o objetivo de promover e ativar processos de aprendizagem que conduzem a disposições, atitudes, capacidades e formas de comportamento consideradas úteis e valiosas pela sociedade.

Observe-se que o filósofo brasileiro começa a sua definição com a ênfase colocada na palavra "intencionalmente", o que significa um planejamento calcado na vontade e visando finalidades estipuladas antecipadamente. Há nessa definição um termo de grande propriedade freudiana que é o vocábulo "personalidade". Em obras que são o alicerce para a compreensão da teoria freudiana (FREUD, 1950, 1951a, 1951b, 1951c) o conceito de personalidade é bastante trabalhado com a apresentação de suas instâncias. A articulação entre os componentes da personalidade é detalhadamente descrita e a dinâmica de funcionamento é ensinada. Sabemos o que o médico e pai da psicanálise quis dizer ao enunciar o que é a personalidade e quais são seus elementos.

É verdadeiro que na segunda metade do século $\mathrm{XX}$, as ideias freudianas tiveram grande aceitação nos Estados Unidos, e como reflexo dessa penetração no meio acadêmico, refiro-me ao estudo de Field e Shour (1967) que naquela época sustentaram "que a psicologia do ego psicanalítico oferece ao educador uma estrutura conceitual pela qual uma ampla lista de fenômenos mentais pode ser compreendida e organizada no processo educativo". Continuamos a respeitar esse ponto de vista e, de modo algum, nesse artigo temos a intenção de derrubar essa prerrogativa. O conhecimento da "psicologia do ego psicanalítico" é rico e valioso para professores em todos os níveis do sistema escolar.

O que propomos para reflexão, e disponibilizamos como argumentação nesse artigo, é que esses conhecimentos não se tornem elementos de distorção da tarefa educativa. Conhecer esse e outros assuntos faz parte do que se espera de um professor, no entanto, nossa ideia é que a filosofia da educação nos traz uma alternativa ao predomínio das instâncias inconscientes. Saber como o ego 
psicanalítico se forma, se mantém e atua na vida da criança e do adolescente, é imprescindível para todos os educadores.

É interessante e faz-se necessário, para melhor andamento dessa análise, contrapor aqui o conceito de personalidade apresentado por Erikson (1976), que foi discípulo do mestre austríaco e depois elaborou sua própria teoria original. Esse é um autor que oferece sustentação à proposta da Educação como formação integral do sujeito, porque incorpora os elementos psicanalíticos sem permitir que os mesmos sufoquem a consciência, a liberdade e a responsabilidade do sujeito. $\mathrm{O}$ pensamento desse antigo seguidor da linha freudiana é marcado principalmente por levar em conta as contingências e circunstâncias sociais e valorizar a ação do sujeito sobre o contexto.

Essa é a guinada que distancia os dois psicólogos e produz um novo olhar sobre o que é a personalidade. Esse afastamento leva a uma definição de personalidade calcada nas experiências vividas pela criança e depois pelo adolescente, inconsciente e conscientemente, nos conflitos enfrentados, nas crises e nas soluções encontradas. É nesse sentido que a crise enfrentada pelo sujeito (ERIKSON, 1976) adquire imenso valor no processo de construção da personalidade. Quando o adolescente consegue dela tomar consciência, entender seu significado e desse modo conduzir suas experiências, está rumando para a conquista da identidade. Essa é uma das ideias norteadoras de nossa posição quanto à formação integral do sujeito.

A consciência se eleva como a categoria crucial e identificadora da condição humana, a qual permite ao sujeito constatar quais foram erros e acertos, organizar os valores, comportamentos e estilo de vida (DEWEY, 1958) e ao mesmo tempo exige do educador um trabalho intenso. O educador é um colaborador da criança e do adolescente, mas somente o próprio sujeito conseguirá estruturar sua consciência. O filósofo norte-americano utiliza, de modo muito feliz, um vocábulo para expressar o processo de formação de cada pessoa. Plasmável é essa palavra, que nos ensina ser a criança alguém ainda não rigidamente constituída, uma pessoa que está se fazendo, tomando forma. Por ser plasmável, a criança necessita da atuação de outras pessoas, sejam da família, da escola e de outras instituições sociais.

Consciência é, pois, um constructo indispensável na pessoa como tal para que essa se reconheça como única e irrepetível, segundo não só a filosofia pragmática, mas de modo geral. Este é, de alguma maneira, praticamente um consenso entre filósofos da educação, tal como (TRIGUEIRO MENDES, 1983) que insiste no fažer consciente como a característica fundamental dos seres humanos. É preciso que a criança comece a descobrir as suas potencialidades, aptidões e limitações para então poder chegar à idade adulta com capacidade de decidir livremente. Desse modo a criança estará no processo de educação integral que fortalece seu ego e lhe assegura as ferramentas necessárias para a constante luta entre as forças internas, os modelos e ideais propostos e a realidade da qual não pode fugir.

Voltando ao problema da compreensão da Educação, não nos esqueçamos que a natureza da educação é filosófica inicialmente (SUCUPIRA LINS, 2013) sem, no entanto, se afastar de suas 
nuances sociológicas, psicológicas, históricas, biológicas, antropológicas e outras. Estudar uma questão pertinente à natureza da educação, tal como compreender o procedimento pedagógico que possibilite à criança e ao jovem se tornarem cidadãos plenos exige uma reflexão nessa totalidade.

Precisamos, além da explicitação do conceito de Educação, oferecer alguns esclarecimentos acerca da ideia de formação integral. O que significa educação integral? Sucupira Lins (2014) analisa a Educação Integral relacionando-a intrinsecamente ao Desenvolvimento da Pessoa Humana, de modo que não se tenha a falsa intuição de que seria apenas uma lista de habilidades adquiridas por alguém ou um conjunto de disciplinas que deverão compor a grade curricular de uma escola.

O significado de Educação Integral é de um processo pleno e abrangente de formação do ser humano que visa uma harmonia estrutural que dá completude à pessoa em todas as suas potencialidades. Somente com o entendimento dessa definição é que se pode partir para uma atividade pedagógica eficaz que vai incluir não só as aprendizagens racionais, mas também o aprimoramento das emoções, não só os conteúdos cognitivos como os sentimentos e percepções do ser humano.

A Educação integral não pode privilegiar uma faceta ou outra e dessa maneira abandonar algumas perspectivas quanto ao Desenvolvimento da Pessoa Humana. Infelizmente o que se observa é um desequilíbrio no processo educacional, encontrando-se ênfase ora nos aspectos cognitivos, ora nos afetivos, outras vezes nos sociais. A formação integral encontra pontos de sustentação em diversas correntes de pensamento. Pode-se fazer uma aproximação com o que Goleman (1995) pretendeu ao desenhar o modelo de inteligência emocional e assim trazer as questões da personalidade estabelecidas por Freud (1951b) para o campo da consciência, da vontade e da liberdade humana. A emoção não mais seria algo fora do controle do sujeito, mas uma aliada nas tomadas de decisão de modo mais consciente. As deliberações que uma pessoa faz precisam ser resultado da coordenação de todos os seus aspectos, e isso é tarefa da educação entendida enquanto um processo essencialmente de formação integral da pessoa.

Lembremo-nos, ademais, que toda ação educativa pressupõe uma teoria ou filosofia da educação e que, por sua vez, toda filosofia da educação tende a uma filosofia moral (OLIVEIRA, 1998) o que nos leva a um encaminhamento da presente reflexão. Partindo-se desta afirmação, selecionamos a questão ética como o pressuposto para a Educação como formação integral do sujeito e a partir dessa tentaremos estudar as possibilidades das relações com a psicanálise.

Muitos filósofos se debruçaram sobre o que é a ética em diferentes épocas e com olhares diversos, alguns deles de grande proeminência desde os séculos anteriores à nossa era. Dentre esses, nós destacamos a filosofia de Aristóteles (séc. IV a. C. 1996) contida na obra Ética a Nicômaco, na qual encaminha o leitor para a felicidade pela prática das virtudes. Oliveira (1998, p. 57) referindo-se ao estagirita, lembra que "o homem ético aristotélico não é produto de ações isoladas, mas de uma razão que supõe a existência de um ethos comunitário" salientando dessa maneira o papel da razão. 
Maritain (1951), o renomado filósofo francês que atuou durante grande extensão do século XX, insiste na premissa da humanidade tendo como característica o fato de ser fundada sobre a razão e a moral, numa abordagem que permanece em nossos dias. Nessa obra, Maritain (1951) recorda a função dos valores éticos na formação da pessoa e retoma a questão crucial da liberdade que permite o discernimento necessário às decisões humanas. Essa forma de ser da pessoa é alcançada pelo processo da Educação. Nesse ponto encontramos um forte distanciamento da probabilidade de uma Educação com referenciais presos ao conceito freudiano de inconsciente e sua força sobre o agir humano. Parecenos que esse é um divisor de águas a ser considerado. Ou se toma como base para a construção da atividade educacional o significado da liberdade humana ou se aceita o domínio do inconsciente sobre a pessoa.

Um elemento que não pode ser desprezado quando se pretende educar uma criança de modo que se torne um sujeito pleno é a motivação que o leva a pensar, agir, e se desenvolver. Nesse sentido, Lickona (1971) oferece algum espaço para a teoria freudiana, na medida em que também essa destaca a força motivacional como energia necessária para o desenvolvimento da personalidade. Faz, esse autor, no entanto, uma ressalva que é a ausência de um estudo pertinente às consequências de se permitir que crianças se deixem levar por suas emoções e tomem decisões que não poderiam ou deveriam.

Ao nos referirmos às emoções, introduzimos o tema central trabalhado por MacIntyre (1984) em seu trabalho sobre filosofia moral e sociedade, alertando contra os resultados do emotivismo como prática que vem substituindo a razão no agir humano. Esse filósofo contemporâneo afirma que vivemos em uma profunda desordem moral porque nos deixamos levar por nossas emoções em vez de nos guiarmos pela razão que nos permite pensar e agir livremente. A educação moral seria altamente prejudicada se pais, professores e outros responsáveis se deixassem levar pelo emotivismo e também as crianças seguissem esse modo de ser.

Corroborando com essa preocupação, Sucupira Lins (2007) enfatiza que a educação moral é necessária, possível e legítima e que acontece mediante um trabalho marcado pelo telos, isto é, por uma finalidade a ser alcançada. A filósofa da educação continua nessa tecla, chamando os educadores à responsabilidade de um comprometimento em sua tarefa com as crianças e jovens, para que possam alcançar essa finalidade da formação integral.

Educação Moral é ensinável, conforme explica Lind (2015) e tem como pressuposto que se conheça o ser humano em sua complexidade. O filósofo alemão trabalha na atualidade com esse objetivo e tem alcançado sucesso em diferentes pesquisas realizadas. Podemos então introduzir as premissas freudianas nessa totalidade de informações que se fazem necessárias para que o processo educacional venha a se realizar a contento. O citado pensador alemão lembra que nós não podemos nos abster de uma atitude educadora frente às crianças que se desenvolvem para que possam atuar democraticamente na sociedade. 
Ética é assim definida como uma atividade construída conscientemente por educadores que mostram aos educandos quais são os passos dessa caminhada. Há que se ter em mente que esses educandos são plasmáveis (DEWEY, 1998) e que interiorizam, muitas vezes inconscientemente, experiências, imagens e desejos. A qualidade de ser plasmável é que garante à criança as mudanças e transformações que lhe permitem o contínuo aperfeiçoamento.

Enquanto educadores que somos, responsáveis pela formação integral do sujeito, juntamente com a família que nos confia seus filhos, como podemos proporcionar essas mudanças e transformações se ficarmos presos ao que não conhecemos? Essa é uma indagação angustiante que surge das leituras da obra de Freud, pois gostaríamos que houvesse maior clareza nos elementos que fazem parte da vida humana e que, no entanto, estão envoltos em sombras, como afirma o mestre austríaco. Decifrar o inconsciente aparece, pois, como exigência primordial para o educador, e isto não é fácil nem lhe é viável, por não ter o preparo adequado nessa área.

Entender que há imensa dificuldade em se construir uma pedagogia que venha a propiciar a formação integral do sujeito é um dos fundamentos da antropologia que se preocupa com a excelência humana (STORK; ECHEVARRIA, 2005). Esses autores partem dos princípios intelectuais da conduta humana, analisam a sensibilidade do sujeito, emoções e sentimentos para chegarem ao diálogo possível entre educação e antropologia com as contribuições da psicanálise também incluídas em sua proposta.

Retomando o ponto central da educação que é a moralidade, convém lembrar que o autor de um ato "deve saber o que está fazendo, e em segundo lugar, deve escolher isto (grifo dos autores)" conforme explicam Dewey e Tufts (1952, p. 176), insistindo ainda na colaboração indispensável da vontade. Essa premissa vai de encontro a uma primazia da força do inconsciente sobre os atos humanos.

Quando nos preocupamos com a formação integral de cada pessoa, indiscutivelmente estamos considerando a formação de seu caráter. Caráter é um conceito que vem adquirindo cada vez mais força e se encontra presente nos estudos de psicólogos, filósofos, educadores e antropólogos. Uma pessoa adulta, a qual já ultrapassou as crises típicas da adolescência e encontrou a sua identidade, tendo construído a sua personalidade, apresentará tudo isso incluindo um caráter estável.

É preciso, porém cautela ao se compreender essa estabilidade, pois "nenhum ser humano, o quão maduro seja, tem um caráter completamente formado” (DEWEY e TUFTS, 1952, p. 177). Isso é coerente com um dos pressupostos mais importantes da educação que é a sua continuidade. Fala-se em educação permanente, muitas vezes de forma errônea, ao se traduzir essa expressão apenas por aquisição de informações sem fim e até por uma escolarização que não termina. A educação é um processo contínuo que se apoia em patamares de solidez na vida de cada pessoa, segundo etapas e degraus pelos quais essa deve passar.

O caráter de uma criança em fase de desenvolvimento pode ser dito como completo para cada uma das fases em que se encontra, mas ao ultrapassá-la e começar a elaborar os elementos constitutivos 
da seguinte, já se deve falar em formação de caráter. Trata-se, pois, de algo in fieri e ao mesmo tempo in factum. O caráter é a qualidade específica do ser humano que tem correção com o autoconhecimento e a sua hierarquização dos valores éticos de modo que possa lhe servir de ponto de partida para as decisões morais.

Ao afirmar que a "autoconsciência prova ser útil para ambos, alunos e professores", Gardner (1999, p. 75) oferece mais uma contribuição para nosso enfoque da formação integral do sujeito como identificação da própria educação. Ninguém ao nascer tem consciência de si mesmo, e não é aleatoriamente e sozinho que chegará a se autoconhecer. Educadores fazem parte do conjunto de variáveis que influenciarão esse processo que se realiza em um contexto social marcante para essa aquisição. A formação integral do sujeito não é algo que possa ser negligenciado.

Diferentes pesquisadores têm se detido na questão da psicanálise enquanto possibilidade de aplicação nas práticas pedagógicas. Hamachek (1985) examina os principais enunciados freudianos e chega à conclusão que para a educação é necessário que se opte por uma "psicologia humanista".

O que significa para esse autor uma "psicologia humanista" e em que seria distinta da psicanálise? Não é a psicanálise uma "psicologia humanista"? Iniciamos com a pergunta definidora respondendo que não há uma forma consensual para conceituar a psicologia humanista, e que de alguma forma, para esse psicólogo, é a que incorpora experiências existenciais às escolhas pessoais, liberdade e responsabilidade (HAMACHEK, 1985). Os ingredientes aqui listados e que são apresentados pelo referido autor se mostram incompatíveis com a preponderância do inconsciente que dominaria as atitudes e comportamentos das pessoas. Quando se pensa em "psicologia humanista", a ideia de subjetividade aparece. O já citado autor lembra que subjetividade é necessariamente consciente e que faz parte da composição total da pessoa. A "psicologia humana" não descarta as contribuições freudianas, sem, contudo, se manter presa a estas.

Podemos entender a "psicologia humanista" como um ponto de equilíbrio que nos dá a oportunidade de conciliar pressupostos fundamentais da psicanálise com as premissas básicas da Educação entendida como formação integral do sujeito. Cabe inclusive lembrar que a formação integral do sujeito é uma preocupação humanista, pois valoriza o ser humano, e nesse caso se estabelece a aproximação argumentativa desejada.

\section{Conclusões}

A discussão aqui apresentada não teve como objetivo fechar o assunto ou chegar a uma conclusão no sentido restrito do termo. Faremos agora algumas considerações que nos parecem adequadas, retomando o essencial exposto para que de modo simples se tenha alguns pontos indicadores de futuros trabalhos. Não temos a arrogância de nos considerarmos especialistas na teoria 
freudiana, apenas procuramos entender como se pode pensar na formação integral do sujeito, área de filosofia da educação, aproveitando ainda que não todos, mas alguns elementos do pensamento trazido pela psicanálise.

O conceito de Educação que serviu de plataforma para nossa reflexão e análise é em si mesmo altamente abrangente ao se referir à formação integral, e por isso, não pode dispensar a consciência plena do indivíduo no comando de sua vida, de seus pensamentos e condutas. Dessa forma, pretender que os pressupostos freudianos sejam base para a educação é não considerar a capacidade de condução da própria vida que o sujeito tem pelo exercício de sua liberdade, razão e vontade.

Sintetizamos dizendo que o educador não pode negligenciar a contribuição da psicanálise nem ignorar as fundamentais descobertas sobre a personalidade humana trazidas por Freud (1951a). Há, no entanto, que se ter cautela quanto a exageros conceituais e principalmente no que diz respeito a relações que nem sempre são possíveis.

Compreender a existência do inconsciente é condição básica e inicial para a atividade de todos os educadores com os educandos, pois esses devem ser entendidos não apenas por suas expressões objetivas, mas concomitantemente pelas manifestações indiretas do que se passa por detrás de sua consciência. Lembrando, no entanto, que em nenhum momento, o educador pode se presumir como psicanalista. Essa pretensão, de certo modo, arruinaria a probabilidade de conciliação entre psicanálise e educação. O que procuramos nesse trabalho foi enfocar a necessidade de não nos deixarmos, enquanto educadores, levar por um extremismo que tudo explica por intervenções do inconsciente, no que se refere aos comportamentos dos educandos.

Ressaltamos a liberdade como característica primordial do ser humano e que é consolidada pela construção da vontade, das virtudes e do aprimoramento da capacidade racional. A razão não precisa ser entendida como oponente aos pressupostos freudianos. Ainda que seja indubitável na teoria freudiana a ênfase no inconsciente, é desejável que se busque uma compreensão de que há um papel específico nesse contexto para a razão. Isso pode parecer um paradoxo, mas é de paradoxos que a educação se faz. São desafios como esse que impulsionam a educação e enriquecem a atividade pedagógica, sem perder de vista que há uma finalidade da qual os educadores não podem se desviar, e que essa é a formação integral do sujeito.

Finalizando, lembramos que a argumentação filosófica aqui apresentada não pretendeu, em momento algum, desmerecer a contribuição dos pressupostos psicanalíticos para a educação. O foco foi dado à necessidade de não se deixar levar pelas ideias amplamente difundidas do poder absoluto do inconsciente. Cabe ao professor organizar seus conhecimentos, de modo a relacionar Freud e a Educação como formação integral do sujeito, com a finalidade da qualidade e da excelência de suas atividades visando o bem dos educandos. 


\section{Referências}

ARISTOTLE. (Século IV a. C.) Ethique à Nicomaque. Paris: Ed. Flammarion, 1996.

DEWEY, J. Experience and Education. Kappa Delta Pi: Pennsylvania State University, 1998. . Experience and Nature. New York: Dover Publications Inc., 1958.

DEWEY, J.; TUFTS, J. Ethics. New York: Henry Holt and Company, 1952.

ERIKSON, E. Identidade, juventude e crise. 2. ed. Trad. Álvaro Cabral. Rio de Janeiro: Zahar Editores, 1976.

FIELD, K.; SCHOUR, E. The Application of Psychoanalytic concepts of Personality Development to the Educative

Process. American Orthopsychiatric Association, New York 1967. Disponível em:

$<$ https://eric.ed.gov/?q=psychoanalysis + and + education\&ft=on\&pg=2\&id=ED018813>. Acesso em: 27 de abril de 2017

FREUD, S. Le moi et le soi. Paris: Payot, 1951a. - Au dela du principe du plaisir. Paris: Payot, $1951 \mathrm{~b}$.

- Cinq léctions de psychanalise. Paris: Payot, 1951c. - Abregé de psychanalise. Paris: PUF, 1950.

GOLEMAN, D. Emotional Intelligence. New York: Bantam Books, 1995.

GARDNER, H. The disciplined mind. New York: Simon \& Shuster Ed., 1999.

HAMACHEK, Don E. Humanistic-Cognitive Applications to Teaching and Learning: TheoreticalPhilosophical Bases. 22 Aug 1985 Paper presented at the Annual Convention of the American Psychological Association (93rd, Los Angeles, CA, August 23-27, 1985). Disponível em: $<$ https://eric.ed.gov/?q=psychoanalysis+and+education\&ft=on\&id=ED262323>. Acesso em: 27 de abril de 2017

LICKONA, T. Developmental Psychology and Early Childhood Education. State Univ. of New York, Cortland. Coll. at Cortland Washington, D.C. 28p.; Paper presented by the Psychology Colloquia Series, State University College at Cortland, New York, April, 1971. Disponível em:

<http:// files.eric.ed.gov/fulltext/ED082836.pdf>. Acesso em: 27 de abril de 2017

LIND, G. Moral ist Lebrbar. Berlin: Lehbar - Logos Verlag, 2015

MACINTYRE, A. After Virtue. Indiana: University Notre Dame Press, 1984. . Ethics and Politics. Cambridge: Cambridge University Press, 2006.

MARITAIN, J. Neuf Leçons sur les Notions Premières de la Philosophie Morale. Paris: Chez Pierre Tequi, 1951. OLIVEIRA, R. J. Utopia e razão. Rio de Janeiro: Ed. da UFRJ, 1998. 
STORK, R. Y. ; ECHEVARRIA, J. A. Fundamentos de Antropologia. Um ideal de Excelência

Humana. Trad. Patricia Carol Dwyer. São Paulo: Instituto Brasileiro de Filosofia e Ciência Raimundo Lúlio, 2005.

SUCUPIRA LINS, M. J. C. Educação integral e o desenvolvimento da pessoa humana. In: Malheiro, J.

Escola com Corpo e Alma, p. 127-134. Curitiba: Ed. CRV.,2014

. Natureza da educação e filosofia da educação. Revista Educação e Contemporaneidade, Salvador: FAEEBA, v. 22, n. 39, p. 115-131, 2013.

.Educação Moral na Perspectiva de Alasdair MacIntyre. Rio de Janeiro: Ed. Access, 2007

. Educação numa perspectiva antropológica freudiana. Revista UNIVILLE, p. 31-38, v. 7, n. 2, dez. 2002.

SUCUPIRA, N. Ética e educação. Presença Filosófica, v. 6, n. 4, p. 28-42, out./dez. 1980.

TRIGUEIRO MENDES, D. Filosofia da educação brasileira. Rio de Janeiro: Civilização Brasileira, 1982. 